University of Nebraska - Lincoln

DigitalCommons@University of Nebraska - Lincoln

Faculty Publications, Department of Psychology

Psychology, Department of

7-20-2006

\title{
Early Predictors of Self-Regulation in Middle Childhood
}

\author{
Rebecca A. Colman \\ University of Nebraska-Lincoln, rebecca.colman@dfa.state.ny.us \\ Sam A. Hardy \\ University of Nebraska-Lincoln \\ Myesha Albert \\ University of Nebraska-Lincoln \\ Marcela Raffaelli \\ University of Nebraska-Lincoln, mraffaelli1@unl.edu \\ Lisa J. Crockett \\ University of Nebraska-Lincoln, ecrockett1@unl.edu
}

Follow this and additional works at: https://digitalcommons.unl.edu/psychfacpub

Part of the Psychiatry and Psychology Commons

Colman, Rebecca A.; Hardy, Sam A.; Albert, Myesha; Raffaelli, Marcela; and Crockett, Lisa J., "Early Predictors of Self-Regulation in Middle Childhood" (2006). Faculty Publications, Department of Psychology. 80.

https://digitalcommons.unl.edu/psychfacpub/80

This Article is brought to you for free and open access by the Psychology, Department of at DigitalCommons@University of Nebraska - Lincoln. It has been accepted for inclusion in Faculty Publications, Department of Psychology by an authorized administrator of DigitalCommons@University of Nebraska - Lincoln. 
Published in Infant and Child Development 15:4 (July/August 2006), pp. 421-437.

Copyright (C 2006 John Wiley \& Sons, Ltd. Used by permission.

Available online in Wiley InterScience http://www.interscience.wiley.com DOI: 10.1002/icd.469

\title{
Early Predictors of Self-Regulation in Middle Childhood
}

\author{
Rebecca A. Colman*, Sam A. Hardy, Myesha Albert, \\ Marcela Raffaelli, and Lisa Crockett \\ University of Nebraska-Lincoln
}

\begin{abstract}
The present study examined the contribution of caregiving practices at ages 4-5 (Time 1) to children's capacity for self regulation at ages 8-9 (Time 2). The multiethnic sample comprised 549 children of National Longitudinal Survey of Youth (NLSY) participants. High levels of maternal warmth and low levels of physically punitive discipline at Time 1 were associated with a greater capacity for self-regulation at Time 2. These associations remained significant once initial levels of self-regulation were taken into account, indicating that the development of self-regulation is open to caregiver influence during childhood. Neither child gender nor ethnicity moderated the effects of early parenting practices on later self-regulation; the interaction between low maternal warmth and high discipline was also non-significant. Findings add to the literature on how early parenting practices shape children's capacity for effective self-regulation, and have implications for researchers and practitioners.
\end{abstract}

Key words: self-regulation, middle childhood, parenting

Acquiring the capacity for effective self-regulation is one of the major challenges of human development. In order to function successfully within their environment and attain desired goals, individuals must learn to control their attention, behaviours, and emotions, and be able to utilize these capacities adaptively when faced with contextual and personal demands (Demetriou, 2000; Zimmerman, 2000). Research examining the links between various aspects of children's capacity for self-regulation and well-being indicates that children who lack an effective, flexible array of self-regulatory skills are at risk of experiencing a wide range of personal and social difficulties. Low levels of inhibitory or attentional control have been associated with low levels of social (Eisenberg, Fabes, Guthrie, \& Reiser, 2000; Eisenberg et al., 1997; Fabes et al., 1999) and cognitive (Brody \& Flor, 1998) competence in school-aged children, a diminished capacity for coping

*Correspondence to: Rebecca Colman, NYS Office of Children and Family Services, South Building, Room 313, 52 Washington Street, Rensselaer, NY 12144 E-mail: rebecca.colman@dfa. 
with anger in preschool-aged boys (Eisenberg, Fabes, Nyman, Bernzweig, \& Pinuelas, 1994) and higher rates of externalizing problems in both children and adolescents (Caspi, Henry, McGee, Moffitt, \& Silva, 1995; Eisenberg et al., 2000; Lengua, 2002). Poor self-regulation may also play a key role in adolescent risk-taking. For example, in longitudinal studies, lower levels of self-regulation in early adolescence were associated with higher levels of sexual risk-taking in mid-adolescence (Raffaelli \& Crockett, 2003), and, among boys, poor self-restraint in preadolescence predicted higher rates of misconduct (Feldman \& Brown, 1993). Thus, research aimed at uncovering factors that contribute to the formation of children's self-regulatory capacities promises to augment our understanding of how to foster positive outcomes in childhood and adolescence.

Although differences in children's capacity to self-regulate are often attributed to early emerging differences in temperament, researchers interested in the development of self-regulation also cite the importance of early parenting practices (Demetriou, 2000; Kopp, 1982). According to Kopp (1982), the development of self-regulation begins in infancy and is marked by a gradual shift from primarily external to primarily internal sources of control. Caregiving interactions play a major role in this transition, with neonates and young infants initially relying heavily on interactions with their caregivers for assistance with basic physical, emotional, and cognitive regulatory tasks, like the soothing of emotional distress and the focusing of attention, and eventually learning through shared regulatory experiences to apply these processes on their own (Committee on Integrating the Science of Early Childhood Development, 2000; Demetriou, 2000; Kopp, 1982). Caregiving interactions expose children to new regulatory skills and strategies and, as such, provide valuable opportunities for practicing and strengthening nascent regulatory abilities. The extent to which individual children succeed in acquiring the skill-based and affective underpinnings of effective self-regulation as a result of these shared regulation experiences, however, is believed to vary with the quality of parenting experienced.

\section{WARM AND RESPONSIVE PARENTING}

Warm, responsive caregiving is believed to foster the development of self-regulatory skills. According to attachment theorists, secure parent-child relationships, in which parents are warm and attentive to children's emotional needs, help to ameliorate early periods of negative affect and teach positive coping skills, increasing the likelihood that future emotional experiences will be effectively managed (Thompson, 1994). Likewise, responsive parenting, in which caregivers are alert and sensitive to child cues and assist children in achieving desired objectives, is believed to expose children to positive strategies for adapting their thoughts, emotions, and behaviours to meet situational demands and to encourage the formation of representations in which the self is portrayed as an effective agent (Sroufe, 1983; Tronick, 1989).

Consistent with these hypotheses, previous research has documented positive associations between warm, responsive caregiving and indicators of emotional and behavioural regulation in infancy and early childhood (e.g. Londerville \& Main, 1981; Tronick, 1989; Vondra, Shaw, Swearingen, Cohen, \& Owens, 2001). Vondra et al. (2001) reported positive associations between attachment security, assessed between 18-24 months, and 24 month assessments of children's task orientation and positive 
affect during teaching tasks. Early attachment security was also found to be negatively associated with maternal reports of externalizing problems at age 3. In addition, researchers interested in early conscience development have repeatedly demonstrated links between responsive parenting practices and both contemporaneous (e.g. Parpal \& Maccoby, 1985) and later measures of child compliance (e.g. Kochanska, 1997; Kochanska \& Murray, 2000). To the extent that compliance with adult commands requires children to modulate their thoughts, behaviours, and emotions in response to external demands, these findings lend additional support to the argument that the capacity for effective self-regulation is enhanced by the experience of warm, responsive parenting early in life.

\section{PHYSICALLY PUNITIVE PARENTING}

In contrast, power assertive and physically punitive practices (e.g. force, threats, deprivation of privileges) may stifle the development of children's self-regulatory skills. Discipline encounters, in which parents attempt to modify children's thoughts, behaviours, and/or emotions in accordance with their own values and expectations, represent a common context in which co-regulation is likely to occur. However, when parental expectations are conveyed in a threatening or punitive manner that is likely to cause over-arousal or anger in the child, the focus of the encounter is believed to shift away from the content of the parent's message and toward the child's reaction to the mode of delivery (Grusec \& Goodnow, 1994). This shift in attention reduces the likelihood that parental strategies for modulating thoughts, behaviours or emotions will be attended to and diminishes the likelihood that the reprimanded child will want to comply with parental expectations. Thus, physically punitive parenting practices may interfere with the development of effective self-regulation strategies by reducing both the opportunity and motivation to engage in effective co-regulatory experiences.

In keeping with this hypothesis, previous research examining the links between parenting practices and child behaviour indicates that parents who engage in high rates of physically punitive and power assertive parenting practices have less well regulated children. Morrell and Murray (2003) found significant associations between indices of coercive and rejecting parenting at 4 months and boys' level of emotional dysregulation and distractibility at 9 months. Several studies have also found associations between harsh parenting practices and higher rates of child defiance (Crockenberg \& Litman, 1990; Power \& Chapieski, 1986), externalizing behaviour (e.g. Conger, Ge, Elder, Lorenz, \& Simons, 1994; Strauss, Sugerman, \& Giles-Sims, 1997), and internalizing problems in adolescence (e.g. McLoyd, Jayaratne, Ceballo, \& Borquez, 1994), suggesting that physically punitive parenting practices may lead to a diminished capacity for both behavioural and emotional self-regulation. Research by Feldman and Wentzel (1990) supports this view; in their study, harsh discipline by both mothers and fathers was negatively associated with male adolescents' capacity for self-restraint.

\section{THE IMPORTANCE OF CONTEXT}

Simply examining the main effects of parental warmth and physical punishment on children's self-regulatory skills may, however, be misleading. Deater-Deckard and Dodge (1997) have argued that the association between physical punishment and 
later externalizing problems (an indicator of poor self-regulation) will vary with both parental and cultural context. In their longitudinal study of childhood aggression, maternal warmth moderated the impact of physical discipline on childhood aggression, such that the relation between physical punishment and externalizing problems was weaker among families who were high in parental warmth. Similarly, previous research indicates that the relation between physical discipline and child outcomes varies across ethnic groups. Deater-Deckard, Dodge, Bates, \& Petit (1996) found significant associations between physical discipline and externalizing problems in children of European-American, but not African-American, descent. This finding suggests that the impact of physical discipline on child outcomes may depend on the extent to which such behaviour is viewed as normative within a particular cultural group.

Finally, the associations found between harsh parenting and later regulatory ability in Morrell and Murray's study (2003) applied only to boys. Male and female infants did not differ, however, in the overall rates at which they experienced harsh parenting practices. This pattern of results suggests that observed gender differences in regulatory capacities were not attributable to differential exposure to particular parenting styles, but rather to differences in the ways in which parenting practices impacted boys' and girls' development.

\section{THE PRESENT STUDY}

To help illuminate how parenting practices shape the development of self-regulation over time, the present study uses data from the National Longitudinal Survey of Youth (NLSY). The NLSY gathers information pertinent to child, parent, and family functioning on a regular basis and thus provides a valuable mechanism for studying the impact of early parenting practices on children's capacity for effective self-regulation later in life. Specifically, we examine the extent to which exposure to both warm and physically punitive parenting practices at ages $4-5$ predicts children's overall ability to modulate their thoughts, behaviours, and emotions at ages 8-9. Drawing on previous research, we anticipated that maternal warmth would be positively associated with children's later self-regulation, whereas physically punitive parenting practices would decrease the likelihood that effective self-regulatory abilities would develop. Moreover, we anticipated that parental context, ethnicity, and child gender would act as potential moderators of this anticipated association. Specifically, we examined whether the presumably negative impact of physically punitive parenting on children's regulatory skills would be more pronounced when mother-child relationships were low in warmth. Associations between physically punitive discipline and self-regulation were also expected to be less pronounced amongst African-American and female children.

In addition, the present study sought to extend prior research on the relations between parenting practices and self-regulation in several important ways. First, previous research examining the role of parenting practices in the development of children's selfregulatory skill has been primarily confined to studies of early infancy and preschoolaged children, although most scholars agree that important self-regulatory capacities, like executive functions, continue to develop into middle childhood (Brocki \& Bohlin, 2004; Bronson, 2000; Kopp, 1982; Raffaelli, Crockett, \& Shen, 2005). As a result, it is largely unknown whether the capacity for self-regulation in middle childhood remains 
open to caregiving influence. The present study addresses this gap by considering the impact of early parenting practices on school-aged children's capacity for effective self-regulation.

Second, the present study utilizes longitudinal, rather than contemporaneous, measures to assess the relations between early parenting and childhood self-regulation. Although previous research supports a connection between parenting practices and regulatory abilities (e.g. Londerville \& Main, 1981; Morrell \& Murray, 2003; Vondra et al., 2001), the use of concurrent and/or closely spaced measures of parent and child behaviour limits our ability to determine causal impacts. Children with different levels of early regulatory skill may simply be more likely than other children to elicit particular parental descriptions and behaviours. For example, children who lack an effective array of regulatory skills may be more likely to elicit harsh parenting as a result of their uncontrolled or inappropriate behaviour. In addition, children who are poor self-regulators at ages 4-5 may be more likely than other children to continue to demonstrate difficulties with regulatory tasks 4 years later. Thus, in order to determine whether parenting practices contribute to the development of children's self-regulatory skill over time and above and beyond early emerging differences in individual capacities, the present study controls for children's initial regulatory capacity when examining the impact of parenting practices on self-regulation 4 years later.

Finally, given previous research documenting associations between maternal-and family-based characteristics, parenting, and self-regulation, the present study also controls for maternal and family demographics when examining the associations between parenting and self-regulation. Specifically, mothers' use of physically punitive and harsh parenting practices has been linked to teen motherhood (e.g. Goerge \& Lee, 1997), low levels of maternal education (e.g. Londerville \& Main, 1981), single parent households (e.g. US Department of Health and Human Services, 1996), and economic distress (e.g. Conger et al., 1994; Elder, Nguyen, \& Caspi, 1985; Lempers, Clark-Lempers, \& Simons, 1989; Wolfner \& Gelles, 1993). Likewise, mothers who have difficulty regulating their own behaviour, as suggested by self-reported histories of delinquent behaviour, may be ill prepared to teach effective self-regulation strategies to their children. The effects of transitioning into motherhood at a young age, low levels of maternal intelligence and educational attainment, single parenthood, family poverty, and maternal delinquency on children's regulatory development are therefore accounted for before differences in parenting practices are considered.

\section{METHOD}

\section{Sample}

Data came from the National Longitudinal Survey of Youth (NLSY), a study sponsored by the US Department of Labor (Zagorsky \& White, 1999). The NLSY began in 1979 with a national probability sample of young adults aged 14-21 living in the US ( $N$ $=12,686$; female $N=6,283$ ). The study originally included oversamples of Blacks, Hispanics, and low SES Whites. Owing to funding cutbacks, the low SES Whites were dropped from the study in 1990 (Zagorsky \& White, 1999). In 1986, children of female participants were added to the study, and have been assessed every 2 years thereafter. The NLSY datasets are publicly available to interested researchers. 
As part of a larger study drawing on the 'Children of the NLSY79' dataset, we identified a cohort of children aged 4-5 in $1986(N=855$; in cases where multiple siblings participated in the study, one sibling was randomly selected for inclusion in the sample). The current analysis utilized mother-report and interviewer-report data from the 1986 (Time 1) and 1990 (Time 2) waves of the NLSY-Children survey when sample children were 4-5 and 8-9 years old, respectively. Additional maternal variables were drawn from earlier rounds of data collection.

The present analytic sample consists of the 549 children (54\% male) who were present at both waves and had complete data on all study variables. Based on NLSY categorizations of race/ethnicity, these children were 23\% Hispanic, 38\% Black, and $39 \%$ non-Hispanic/non-Black. The 549 children included in the sample were compared on all study variables to the 306 who were either lost to follow-up $(N=113)$ or excluded due to missing data $(N=193)$. The two groups differed significantly on AFQT scores, a measure used to assess intelligence, $F(1,782)=13.46, p<0.001, d=0.26$; maternal education, $F(1,847)=7.68, p<0.001, d=0.19$; and maternal warmth, $F(1,830)=$ $4.57, p<0.05, d=0.15$. Children in the analytic sample had mothers who had higher intelligence test scores, were more likely to have received a high school diploma and exhibited higher levels of maternal warmth than children not included in the sample. No other differences were found. The modest effect sizes indicate that attrition-related bias was unlikely to be a major problem.

\section{Measures}

Measures included child demographics, maternal and family characteristics, parenting variables and child characteristics (see Table 1 for descriptive stastistics).

\section{Child gender}

Child gender was coded as 0 (male) and 1 (female).

\section{Child race/ethnicity}

Child race/ethnicity was coded in the NLSY dataset as Hispanic, Black, or nonHispanic/non-Black, based on maternal report. (The non-Hispanic/non-Black group

Table 1. Descriptives of study variables

\begin{tabular}{llcr}
\hline Variables & Range & $M$ & S.D. \\
\hline Household composition & $0-1$ & 0.61 & 0.49 \\
Poverty status & $0-1$ & 0.36 & 0.48 \\
Maternal delinquency & $0-2.45$ & 0.39 & 0.33 \\
Maternal intelligence & & & \\
(ARQT percentile) & $0-100$ & 30.15 & 23.82 \\
Age at first birth & $14-25$ & 19.0 & 2.27 \\
Maternal education & $0-1$ & 0.74 & 0.44 \\
Maternal warmth & $0-1$ & 0.69 & 0.29 \\
Physical discipline & $0-2$ & 1.27 & 0.75 \\
Self-regulation, Time 1 & $1-3$ & 2.49 & 0.32 \\
Self-regulation, Time 2 & $1-3$ & 2.54 & 0.35 \\
\hline
\end{tabular}

$N=5.9$. 
consists primarily of European Americans and is hereafter referred to as White; Zagorsky $\&$ White, 1999.) For regression analyses, two dummy code variables (Hispanic versus other, Black versus other) were created using Whites as the omitted category.

\section{Household composition (Time 1)}

Mothers' responses to multiple items regarding household membership were used to create a variable indicating whether the child lived in a mother-only household (coded as 0) or two-adult household (i.e. father, spouse, or partner also in residence, coded as 1).

\section{Poverty status (Time 1)}

The dichotomous measure of poverty status was based on mother's report of income in 1986. Responses were coded as 0 (not in poverty) or 1 (in poverty). Poverty status was determined based on whether a family was above or below the poverty level for the past year, using criteria established by the Center for Human Resources Research.

\section{Maternal intelligence}

In 1981, mothers completed the Armed Services Vocational Aptitude Battery, which assesses aptitude and skills in a variety of domains. Scores reflecting verbal, math, and reasoning skills are derived from a subset of this battery known as the Armed Forces Qualification Test (AFQT) (Zagorsky \& White, 1999). AFQT percentile scores were used as a proxy for maternal intelligence.

\section{Mother's age at first birth}

In the 1986 survey wave, mothers reported how old they were when they had their first child.

\section{Maternal education (Time 1)}

Mother's education status in 1986 was coded as 0 (no high school diploma/ GED) or 1 (high school diploma/GED or higher degree).

\section{Maternal delinquency}

Mothers' responses to 17 self-report items included in the 1980 survey wave were averaged (alpha $=0.70)$. Individual items were scored using a 6-point scale ranging from (never) to (50 or more times) and were designed to tap into how often mothers had participated in a wide array of delinquent acts (e.g. shoplifting, auto theft) within the past year (Zagorsky \& White, 1999).

\section{Maternal warmth (Time 1)}

A measure of maternal warmth was derived from four dichotomous interviewer report items (e.g. 'mother/guardian's voice conveyed positive feeling about this child') coded as 0 (no) or 1 (yes). Items were averaged to create a composite scale score $($ alpha $=0.67)$. 
Physically punitive discipline (Time 1)

Two mother-report items were combined to create a measure of physically punitive discipline. The first item asked how often mothers had spanked their child in the past week, and was recoded into a yes/no variable to reduce skewness. The second item assessed mothers' endorsement of non-physically punitive (e.g. ground child, take away privileges, send to room) and physically punitive (e.g. spank, slap) responses to a hypothetical situation in which their child had hit them. Mothers could endorse multiple responses and provide their own strategy (coded as "other"). Mothers were categorized according to whether or not they indicated they would use any physically punitive response (scored as yes/no). Responses from these two recoded items were summed to create a physically punitive discipline composite. The total score could range from 0 to 2 , with a higher score indicating greater use of physically punitive discipline.

\section{Child self-regulation}

The measure of self-regulation (Time 1 and Time 2) was derived from 12 items from the Behavior Problems Index (Peterson \& Zill, 1986; Zill, 1990). Consistent with the concepts of ego control and ego resilience put forth by Block and Block (1980), our definition of self-regulation encompasses both a general capacity for the regulation of behaviour as well as the ability to regulate attention and affect in accordance with contextual demands (Kopp, 1982). Items corresponded to the three conceptual domains of self-regulation; for example, "he/she has sudden changes in mood or feeling" was an indicator of affect regulation, "he/she has difficulty concentrating" was an indicator of attention regulation, and "he/she is restless or overly active, cannot sit still" was an indicator of behavioural regulation (all 12 items can be found in the appendix). Mothers reported how well each item described their child's behavior in the last 3 months, using a 3-point scale: 1 (often true), 2 (sometimes true) and 3 (not true). To ensure that the measure of self-regulation did not overlap with pre-existing externalizing problems, items indicative of antisocial behaviour (e.g. bullying, lying, breaking things deliberately), peer problems (e.g. trouble getting along with others, not liked) and oppositional behavior (e.g. disobedience, arguing) were excluded. Similar items to those included in the self-regulation measure have been utilized in developmental research that examines self-regulation and self-control (e.g. Eisenberg et al., 1995; Feldman \& Brown, 1993; Lengua, West, \& Sandler, 1998). Moreover, the ability of the present scale to capture meaningful differences in children's regulatory skill has been documented in previous research. Consistent with theoretical expectations, Raffaelli and Crockett (2003) found lower levels of self-regulation in early adolescence predicted sexual risk-taking 4 years later.

Confirmatory factor analysis indicated that a single factor solution provided an adequate fit to the data at each time point (Raffaelli et al., 2005). A total score was computed by averaging across the items for each year (Time 1 , alpha $=0.79$; Time 2, alpha $=0.84)$. Higher scores correspond to higher levels of self-regulation.

\section{Analysis Plan}

Research questions were addressed with three basic sets of analyses. First, in preliminary analyses, differences in parenting across gender and ethnic groups were examined via analysis of variance, and bivariate associations among the study variables were examined 
by computing correlations. Cohen's d effect sizes were calculated for all significant gender and ethnic group mean differences. Next, multiple regression analyses predicting Time 2 self-regulation were conducted, with demographics and family characteristics, parenting, and Time 1 self-regulation entered on successive steps. Third, interaction terms (computed with centred variables) were added on the last step of the regressions to test for two-way interactions between maternal warmth and physically punitive discipline, parenting variables and ethnicity, and parenting variables and gender.

\section{RESULTS}

\section{Preliminary Analyses}

Preliminary analyses revealed several gender and ethnic differences in the primary study variables (Table 2). First, girls had significantly higher scores than boys on Time 2 self-regulation, $F(1,547)=5.12, p<0.05, d=0.19$. There were no gender differences in Time 1 self-regulation, maternal warmth, or physically punitive discipline. Second, there were significant ethnic differences in maternal warmth, $F(2,546)=7.44, p<$ 0.01 and physically punitive discipline, $F(2,546)=4.80, p<0.01$, but not Time 1 or Time 2 self-regulation. Pairwise comparisons using LSD (minimum mean difference $=0.62)$ revealed that Whites were higher on maternal warmth than Hispanics $(d=$ $0.23)$ and Blacks $(d=0.37)$; however, differences between Hispanics and Blacks were not significant. LSD pairwise comparisons (minimum mean difference $=0.14$ ) for ethnic differences in physically punitive discipline indicated that Blacks were higher in physically punitive discipline than Hispanics $(d=0.29)$ and Whites $(d=0.26)$, but there were no significant differences between Hispanics and Whites.

Correlations among study variables are reported in Table 3. Confirming the ANOVA results, being female was associated with higher Time 2, but not Time 1, selfregulation. In addition, poverty status, maternal delinquency, and physically punitive discipline were all negatively associated with self-regulation at both waves. Maternal intelligence was positively related to Time 1 and Time 2 self-regulation. Maternal warmth was positively correlated with Time 2 , but not Time 1 self-regulation. Time 1 self-regulation was positively associated with Time 2 self-regulation. All the child demographics (ethnicity and gender) and family background variables (household

Table 2. Gender and ethnic differences in self-regulation and parenting

\begin{tabular}{|c|c|c|c|c|c|c|c|c|}
\hline & \multicolumn{8}{|c|}{ Self-Regulation } \\
\hline & \multicolumn{2}{|c|}{ Time 1} & \multicolumn{2}{|c|}{ Time 2} & \multicolumn{2}{|c|}{ Maternal Warmth } & \multicolumn{2}{|c|}{ Physically punitive disc } \\
\hline & M & S.D. & M & S.D. & $M$ & S.D. & $M$ & S.D. \\
\hline \multicolumn{9}{|l|}{ Gender } \\
\hline Male & $2.48^{\mathrm{a}}$ & 0.33 & $2.50^{\mathrm{a}}$ & 034 & $0.68^{a}$ & 0.29 & $1.24^{\mathrm{a}}$ & 0.77 \\
\hline Female & $2.51^{\mathrm{a}}$ & 0.30 & $2.57^{\ddagger}$ & 036 & $0.71^{\mathrm{a}}$ & 0.29 & $130^{4}$ & 0.73 \\
\hline \multicolumn{9}{|l|}{ Ethnicity } \\
\hline White & $2.48^{a}$ & 0.33 & $2.53^{\mathrm{a}}$ & 0.35 & $0.75^{a}$ & 0.27 & $1.20^{\mathrm{a}}$ & 0.79 \\
\hline Hispanic & $2.48^{\mathrm{a}}$ & 0.32 & $2.54^{\mathrm{a}}$ & 036 & $0.68^{\mathrm{b}}$ & 031 & $1.18^{\mathrm{a}}$ & 0.77 \\
\hline Black & $2.51^{\mathrm{a}}$ & 0.31 & $2.54^{a}$ & 0.35 & $0.64^{\mathrm{b}}$ & 0.29 & $1.40^{\circ}$ & 0.67 \\
\hline
\end{tabular}

$N=5.9$.

Means in the same column that do not share subscripts differ at $p<0.05$. 


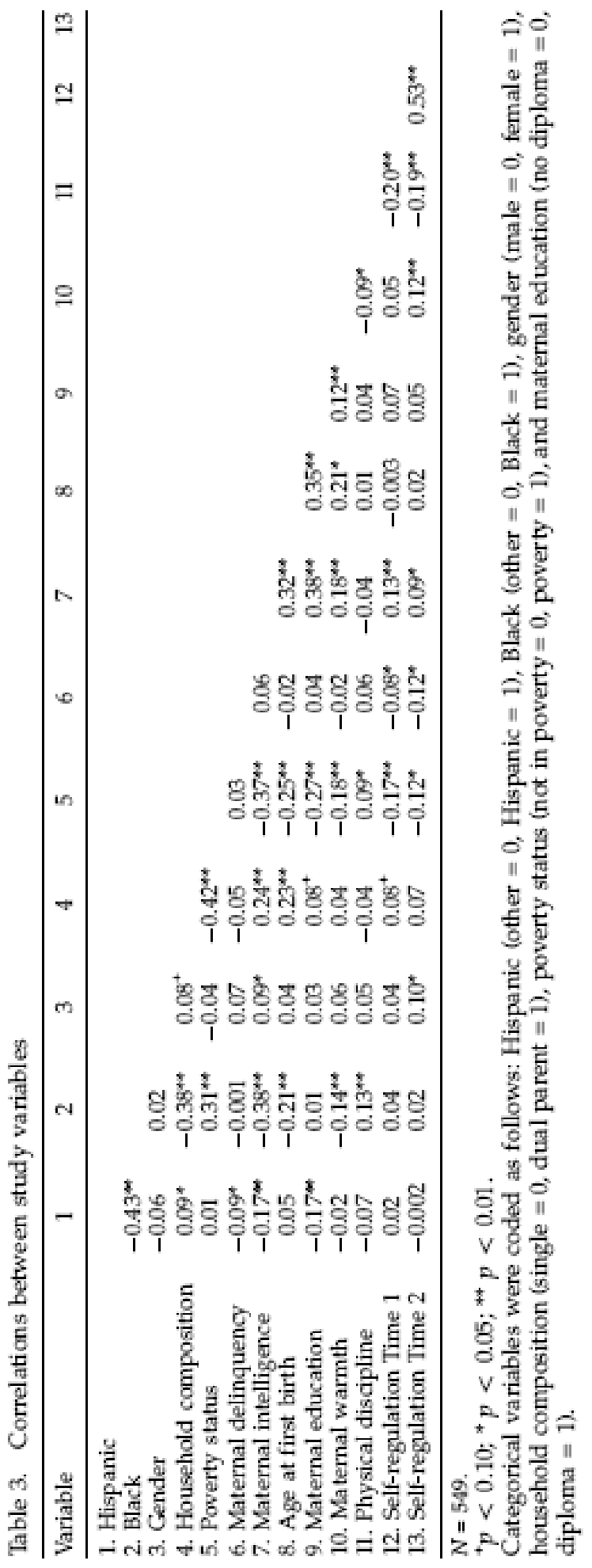


composition, poverty status, maternal intelligence, age at first birth, and maternal education) were at least marginally $(p s<0.10)$ associated with one or more indicators of parenting or self-regulation. Given these associations, as well as the theoretical relevance of the background variables discussed earlier, all child demographic and family background variables were included in the regression analyses.

\section{Longitudinal Analyses Predicting Middle Childhood Self-Regulation}

Multiple regressions were conducted in which self-regulation at Time 2 was regressed on parenting factors assessed 4 years earlier (Table 4). Gender, ethnicity, and family background variables were entered in the first step, $R^{2}=0.05, F(9,539)=3.18, p<$ 0.01 . Gender predicted self-regulation such that girls had higher self-regulation scores at Time 2 than boys. Being Black was also linked with higher Time 2 self-regulation. Poverty and maternal delinquency were both negatively associated with Time 2 selfregulation, such that children from homes above the poverty line, and children with mothers who reported lower rates of delinquency, had significantly higher Time 2 self-regulation than children from homes below the poverty line, and children whose mothers reported higher delinquency. Household composition, maternal intelligence, mother's age at first birth, and maternal education were not significantly associated with self-regulation on this step or on subsequent steps.

In the second step, maternal warmth and maternal physically punitive discipline were entered into the model resulting in a significant increase in $R^{2}, R^{2} \Delta=0.04, F \Delta(2,537)$ $=11.78, p<0.001$. Children whose mothers demonstrated higher levels of warmth or lower levels of physically punitive discipline at Time 1 had significantly higher selfregulation at Time 2 than did children whose mothers were low on warmth or high on physically punitive discipline. With inclusion of the parenting variables in the model,

Table 4. Hierarchical regressions of Time 1 maternal warmth and maternal harsh discipline predicting time 2 self-regulation

\begin{tabular}{lccc}
\hline Variables entered & Model & \\
\cline { 2 - 4 } & 1 & 2 & 3 \\
\hline Hispanic & 0.06 & 0.07 & 0.02 \\
Black & $0.12^{*}$ & $0.15^{* *}$ & 0.05 \\
Gender & $0.09^{*}$ & $0.10^{*}$ & $0.08^{*}$ \\
Household composition & 0.03 & 0.04 & 0.02 \\
Poverty status & $-0.11^{*}$ & $-0.08^{+}$ & -0.02 \\
Maternal delinquency & $-0.12^{* *}$ & $-0.11^{* *}$ & -0.08 \\
Maternal Intelligence & $0.11^{+}$ & $0.10^{+}$ & 0.02 \\
Age at first birth & -0.03 & -0.04 & -0.01 \\
Maternal education & 0.01 & 0.01 & 0.01 \\
Maternal warmth & & $0.09^{*}$ & $0.08^{*}$ \\
Maternal physical discipline & & $-0.18^{*+*}$ & $-0.08^{*}$ \\
Self-regulation, Time 1 & & $0.09^{*+*}$ & $0.49^{* * *}$ \\
$R^{2}$ & $0.05^{* *}$ & & $0.30^{* * *}$ \\
\hline
\end{tabular}

Values are standardized regression coefficients.

$N=549 ;{ }^{+} p<0.10 ;{ }^{*} p<0.05 ; * * p<0.01 ; * *+p<0.001$.

Categorical variables were coded as follows: Hispanic (other $=0$, Hispanic $=1$ ), Black (other $=0$, Black $=1$ ), gender (male $=0$, female $=1$ ), household composition (single $=0$, dual parent $=1$ ), poverty status (not in poverty $=0$, poverty $=1$ ), and maternal education ( no diploma $=0$, diploma $=1$ ). 
Black ethnicity, gender, and maternal delinquency remained significant predictors of Time 2 self-regulation.

Time 1 self-regulation was added at the third step to examine the extent to which parenting in early childhood was associated with middle childhood self-regulation above and beyond individual differences in early childhood self-regulation. This resulted in a significant increase in $\mathrm{R}^{2}, R^{2} \Delta=0.21, F \Delta(1,536)=163.63, p<0.001$. The final model accounted for a significant amount of the variance in Time 2 self-regulation, $R^{2}=0.30$, $F(12,536)=19.42, p<0.001$. Time 1 self-regulation was the strongest predictor of Time 2 self-regulation. Not surprisingly, the strong association between Time 1 and Time 2 self-regulation led to a decrease in the predictive utility of other variables in the model. Of the control variables (child demographics and family background), only gender remained significantly linked to Time 2 self-regulation. However, even after controlling for Time 1 self-regulation, maternal warmth and physically punitive discipline remained significantly related to Time 2 self-regulation.

Finally, three additional regression models (not shown) were computed to test for the hypothesized interactions. One regression examined the interaction between the two parenting constructs (maternal warmth and physically punitive discipline). The second assessed interactions between the two parenting constructs and gender, and the third between the two parenting constructs and ethnicity. In each analysis, the original regression analysis was recomputed adding the interaction term or terms on the fourth step. Contrary to expectations, none of the interaction terms significantly improved the predictive utility of the original regression model.

\section{DISCUSSION}

Researchers interested in the antecedents of self-regulation have cited the importance of early caregiving interactions to the acquisition and development of children's self-regulatory abilities (e.g. Demetriou, 2000; Kopp, 1982). Consistent with this perspective, the current longitudinal analysis revealed significant associations between maternal warmth and mothers' use of physically punitive discipline in early childhood, and the capacity for self-regulation 4 years later. As anticipated, children whose mothers were warmer and relied less on physically punitive parenting strategies during early childhood were more likely than other children to be described as competent regulators of their attention, behaviours, and emotions in middle childhood. Importantly, these associations remained significant even when children's initial level of self-regulation was taken into account.

The observed impact of warmth and physically punitive parenting on later selfregulation is noteworthy for several reasons. First, the present study is unique in demonstrating an effect of parenting practices over an extended period of time. While other studies (e.g. Kochanska \& Murray, 2000; Morrell \& Murray, 2003; Vondra et al., 2001) have reported links between early parenting indices and later aspects of selfregulation, current findings expand this work by documenting an impact of parenting practices over a 4 year time period.

Second, the results clarify the importance of parenting practices to the development of children's regulatory capacities by accounting for initial levels of self-regulation. 
Most previous studies of early parenting and later self-regulation have not controlled for children's prior self-regulatory skill, greatly limiting the capacity to infer causal direction. That is, children with effective self-regulatory skills may be more likely to elicit responsive caregiving, whereas low levels of self-regulatory skill may lead to more punitive parenting practices. In the present study, the effects of parenting practice were examined with children's initial level of self-regulation controlled. The results indicated that maternal warmth and physical discipline at ages 4-5 continued to predict children's capacity for self-regulation at ages $8-9$, even when children's regulatory capacity at ages $4-5$ was taken into account.

Thus, although individual differences in the capacity for self-regulation may emerge early in life and remain fairly stable over time, as suggested by the significant association between Time 1 and Time 2 self-regulation (see also Raffaelli et al., 2005), knowledge of early parenting practices appears to offer useful information about the quality of children's regulatory capacities in middle childhood. Consistent with ideas put forth by attachment and moral development researchers (e.g. Grusec \& Goodnow, 1994; Hoffman, 1983), our findings suggest that parental warmth fosters the growth of regulatory skills. In contrast, physically punitive discipline strategies likely to arouse anger or fear in children may interfere with the establishment of effective co-regulatory cycles, reducing the likelihood that children will acquire regulatory skills through disciplinary encounters. Moreover, although children who are poor self-regulators in early childhood continue to be less adept than their peers at self-regulation in middle childhood, their self-regulatory capacities appear to be open to caregiving influence, suggesting a potential avenue for intervention. Specifically, programs that support warm and responsive parenting practices, and encourage parents to reduce their reliance on physically punitive disciplinary strategies, may enhance children's ability to regulate their attention, behaviours, and emotions later in life.

The present study also sought to expand current thinking on the relations between parenting and the development of self-regulation by incorporating potential contextual effects, such as other parenting practices and child characteristics. We anticipated that interactions would emerge between warmth and physically punitive discipline, parenting practices and child gender, and parenting practices and child race/ethnicity. Contrary to expectations, none of these contextual factors moderated the relations between early parenting practices and self-regulation in middle childhood. That is, having a parent-child relationship high in maternal warmth did not attenuate the observed negative association between physically punitive parenting and later selfregulation. Moreover, warmth appeared beneficial and physical discipline appeared detrimental to the development of self-regulation across ethnicity and gender. Although unexpected, these results are not entirely inconsistent with past research; for example, Deater-Deckard et al. (1996) finding of ethnic group differences in the relation between physical discipline and later externalizing behaviour was limited to teacher and peer reports of children's externalizing behaviours. As in the present study, ethnic differences were not found when maternal reports of child behaviour were used.

It should be noted that the effects of parenting practices on children's subsequent selfregulatory ability were modest $\}$ maternal warmth and physically punitive discipline accounted for about $4 \%$ of the variance observed in children's regulatory capacities. 
The 4-year interval between Time 1 parenting and Time 2 self-regulation likely attenuated the associations between these variables. In addition, data constraints may have contributed to the modest effect sizes. Use of an existing dataset always involves trade-offs. In this case, our ability to examine linkages between core study variables was constrained by the operationalization of key constructs within the NLSY dataset. The variables used to measure warm, responsive parenting and physically punitive discipline strategies within the NLSY reflect only a subset of both positive and punitive parenting behaviours. Likewise, our measure of self-regulation, though conceptually derived and supported by confirmatory factor analysis, was derived from items intended to assess behaviour problems rather than normative aspects of self-regulation. As a result, the measure may not be sensitive to differences within the normative/average range, limiting our ability to make fine discriminations among children who were not exhibiting behaviour problems. These limitations would presumably weaken our ability to detect associations between early parenting and later regulatory skill. The fact that significant links between early parenting and later self-regulation were found in spite of these limitations is noteworthy and merits further exploration. Specifically, studies utilizing measures that incorporate a greater variety of parenting strategies and self-regulatory skills and utilize multiple reporters are recommended.

Another finding that merits additional exploration was that, even though mothers of Black children received higher scores on physically punitive discipline than mothers of either White or Hispanic children, Black children exhibited higher levels of selfregulation at Time 2. It should be noted, however, that our bivariate analyses did not reveal racial differences in Time 1 or Time 2 self-regulation (Table 2). Nor did race predict Time 2 self-regulation once levels of self-regulation at Time 1 were taken into account (Table 4). Race contributed to the prediction of self-regulation at Time 2 only when considered in conjunction with the other demographic variables entered in the model, suggesting a suppressor effect. Given that being Black in our sample is also associated with being poor and with lower maternal intelligence, it is possible that once these negative influences on self-regulation are accounted for, a positive association emerges between being Black and later self-regulation. Future studies should attempt to distinguish racial and demographic effects on later self-regulation.

In conclusion, the present study adds to prior research by demonstrating long-term effects for both maternal warmth and physically punitive parenting practices on selfregulation above and beyond that made by prior self-regulatory skill. These findings help clarify how early parenting practices shape children's capacity for effective selfregulation in middle childhood, and have important implications for researchers and practitioners interested in fostering children's self-regulatory skills.

\section{ACKNOWLEDGEMENTS}

This research was funded by a grant to M. Raffaelli and L. J. Crockett from the National Institute of Mental Health and the National Institute of Child Health and Human Development (R01-MH62977). Research assistance was provided by Jennifer Bowers and Kristin Moilanen. 


\section{APPENDIX A: ITEMS INCLUDED IN SELF-REGULATION MEASURE}

$1 \mathrm{He} /$ she has sudden changes in mood or feeling.

$2 \mathrm{He} / \mathrm{she}$ is too fearful or anxious.

$3 \mathrm{He} / \mathrm{she}$ is unhappy, sad, or depressed.

$4 \mathrm{He} /$ she cries too much.

$5 \mathrm{He} / \mathrm{she}$ is rather high strung, tense, nervous.

$6 \mathrm{He} / \mathrm{she}$ is stubborn, sullen, or irritable.

$7 \quad \mathrm{He} / \mathrm{she}$ has a very strong temper and loses it easily.

$8 \mathrm{He} / \mathrm{she}$ has difficulty concentrating, cannot pay attention for long.

$9 \mathrm{He} / \mathrm{she}$ is easily confused, seems to be in a fog.

$10 \mathrm{He} / \mathrm{she}$ is impulsive, or acts without thinking.

$11 \mathrm{He} / \mathrm{she}$ has a lot of difficulty getting his/her mind off certain thoughts (has obsessions).

$12 \mathrm{He} / \mathrm{she}$ is restless or overly active, cannot sit still.

\section{REFERENCES}

Block, J. H., \& Block, J. (1980). The role of ego-control and ego-resiliency in the organization of behavior. In W. A. Collins (Ed.), Development of cognition, affect and social relations: The Minnesota symposia on child psychology, vol. 13 (pp. 39-101). Hillsdale, NJ: Erlbaum.

Brocki, K. C., \& Bohlin, G. (2004). Executive functions in children aged 6 to 13: A dimensional and developmental study. Developmental Neuropsychology, 26(2), 571-593.

Brody, G. H., \& Flor, D. L. (1998). Maternal resources, parenting practices, and child competence in rural, single-parent African American families. Child Development, 69, 803-816.

Bronson, M. B. (2000). Self-regulation in early childhood: Nature and nurture. New York: Guilford.

Caspi, A., Henry, B., McGee, R. O., Moffitt, T. E., \& Silva, P. A. (1995). Temperamental origins of child and adolescent behavior problems: From age three to fifteen. Child Development, 66(1), $55-68$.

Cohen, J. (1988). Statistical power analysis for the behavioral sciences (2nd ed.). Hillsdale, NJ: Erlbaum.

Committee on Integrating the Science of Early Childhood Development. (2000). From neurons to neighborhoods: The science of early childhood development. Washington, DC: National Academy Press.

Conger, R. D., Ge, X., Elder, G. H., Lorenz, F. O., \& Simons, R. L. (1994). Economic stress, coercive family process and developmental problems of adolescents. Child Development, 65, 541-561.

Crockenberg, S., \& Litman, C. (1990). Autonomy as competence in 2 year olds: Maternal correlates of child defiance, compliance, and self assertion. Developmental Psychology, 26, 961-971.

Deater-Deckard, K., \& Dodge, K. A. (1997). Externalizing behavior problems and discipline revisted: Nonlinear effects and variation by culture, context, and gender. Psychological Inquiry, 8(3), 161-175.

Deater-Deckard, K., Dodge, K. A., Bates, J. E., \& Petit, G. S. (1996). Discipline among African American and European American mothers: Links to children's externalizing behaviors. Developmental Psychology, 32, 1065-1072.

Demetriou, A. (2000). Organization and development of self-understanding and self-regulation: Toward a general theory. In M. Boekaerts, P. R. Pintrich, \& M. Zeidner (Eds.), Handbook of selfregulation (pp. 209-251). San Diego, CA: Academic. 
Eisenberg, N., Fabes, R. A., Guthrie, I. K., \& Reiser, M. (2000). Dispositional emotionality and regulation: Their role in predicting quality of social functioning. Journal of Personality and Social Psychology, 78, 136-157.

Eisenberg, N., Fabes, R. A., Murphy, B., Maszk, P., Smith, M., \& Karbon, M. (1995). The role of emotionality and regulation in children's social functioning: A longitudinal study. Child Development, 66, 1360-1384.

Eisenberg, N., Fabes, R. A., Nyman, M., Bernzweig, J., \& Pinuelas, A. (1994). The relations of emotionality and regulation to children's anger-related reactions. Child Development, 65, 109128.

Eisenberg, N., Fabes, R. A., Shepard, S. A., Murphy, B. C., Guthrie, I. K, Jones, S., Friedman, J., Poulin, R., \& Maszk, P. (1997). Contemporaneous and longitudinal prediction of children's social functioning from regulation and emotionality. Child Development, 68(4), 642-664.

Elder, G. H., Nguyen, T. V., \& Caspi, A. (1985). Linking family hardship to children's lives. Child Development, 56, 361-375.

Fabes, R. A., Eisenberg, N., Jones, S., Smith, M., Guthrie, I., Poulin, R., Shepard, S., \& Friedman, J. (1999). Regulation, emotionality, and preschoolers' socially competent peer interactions. Child Development, 70, 432-442.

Feldman, S. S., \& Brown, N. L. (1993). Family influences on adolescent male sexuality: The mediational role of self-restraint. Social Development, 2, 15-35.

Feldman, S. S., \& Wentzel, K. R. (1990). The relationship between parenting styles, sons' selfrestraint, and peer relations in early adolescence. Journal of Early Adolescence, 10, 439-454.

Goerge, R. M., \& Lee, J. B. (1997). Abuse and neglect of children. In R.A. Maynard (Ed.), Kids having kids: Economic costs and social consequences of teen pregnancy (pp. 205-230). Washington, DC: The Urban Institute Press.

Grusec, J. E., \& Goodnow, J. J. (1994). Impact of parental discipline methods on the child's internalization of values: A reconceptualization of current points of view. Developmental Psychology, 30, 4-19.

Hoffman, M. L. (1983). Affective and cognitive processes in moral internalization. In E.T. Higgins, D. Ruble, \& W. W. Hartup (Eds.), Social cognition and social development: A sociocultural perspective (pp. 236-274). New York: Cambridge University Press.

Knight, G. P., Tein, J. Y., Shell, R., \& Roosa, M. (1992). The cross-ethnic equivalence of parenting and family interaction measures among Hispanic and Anglo-American families. Child Development, 63, 1392-1403.

Kochanska, G. (1997). Mutually responsive orientation between mothers and their young children: Implications for early socialization. Child Development, 68, 94-112.

Kochanska, G., \& Murray, K. T. (2000). Mother-child mutually response orientation and conscience development: From toddler to early school age. Child Development, 71, 417-431.

Kopp, C. B. (1982). Antecedents of self-regulation: A developmental perspective. Developmental Psychology, 18, 199-214.

Lengua, L. J. (2002). The contribution of emotionality and self-regulation to the understanding of children's response to multiple risk. Child Development, 73, 144-161.

Lengua, L., West, S. G., \& Sandler, I. N. (1998). Temperament as a predictor of symptomatology in children: Addressing contamination of measures. Child Development, 69, 164-181.

Lempers, J. D., Clark-Lempers, D., \& Simons, R. L. (1989). Economic hardship, parenting and distress in adolescence. Child Development, 60, 25-39.

Londerville, S., \& Main, M. (1981). Security of attachment, compliance, and maternal training methods in the second year of life. Developmental Psychology, 17, 289-299. 
McLoyd, V., Jayaratne, T. E., Ceballo, R., \& Borquez, J. (1994). Unemployment and work interruption among african american single mothers: Effects on parenting and adolescent socioemotional functioning. Child Development, 65, 562-589.

Morrell, J., \& Murray, L. (2003). Parenting and the development of conduct disorder and hyperactive symptoms in childhood: A prospective longitudinal study from 2 months to 8 years. Journal of Child Psychology and Psychiatry, 44, 489-508.

Parpal, M., \& Maccoby, E. E. (1985). Maternal responsiveness and subsequent child compliance. Child Development, 56, 1326-1334.

Peterson, J. L., \& Zill, N. (1986). Marital disruption, parent-child relationships, and behavioral problems in children. Journal of Marriage and the Family, 48, 295-307.

Power, T.G., \& Chapieski, M. L. (1986). Childrearing and impulse control in toddlers: A naturalistic investigation. Developmental Psychology, 22, 271-275.

Raffaelli, M., \& Crockett, L. (2003). Predicting sexual risk-taking: The role of self-regulation and attraction to risk. Developmental Psychology, 39, 1036-1046.

Raffaelli, M., Crockett, L. J., \& Shen, Y. L. (2005). Developmental stability and change in selfregulation from childhood to adolescence. Journal of Genetic Psychology, 166, 54-75.

Sroufe, L. A. (1983). Infant-caregiver attachment and patterns of adaptation in preschool: The roots of maladaption and competence. In M. Perlmutter (Ed.), Development and policy concerning children with special needs: Volume 16. Minnesota symposia on child psychology (pp. 41-83). Hilsdale, NJ: Erlbaum.

Strauss, M. A., Sugarman, D. B., \& Giles-Sims, J. (1997). Spanking by parents and subsequent antisocial behavior of children. Archives of Pediatric and Adolescent Medicine, 151, 761-767.

Thompson, R. A. (1994). Emotion regulation: A theme in search of definition. Monographs for the Society for Research in Child Development, 59 (2-3), 25-52.

Tronick, E. Z. (1989). Emotions and emotional communication in infants. American Psychologist, 44, 112-119.

US Department of Health and Human Services (1996). Third national incidence study of child abuse and neglect: Final report (NIS-3). National Center on Child Abuse and Neglect Washington, DC: Government Printing Office.

Vondra, J.I., Shaw, D. S., Swearingen, L., Cohen, M., \& Owens, E. B. (2001). Attachment stability and emotional and behavioral regulation from infancy to preschool age. Development and Psychopathology, 13, 13-33.

Wolfner, G. D., \& Gelles, R. J. (1993). A profile of violence toward children: A national study. Child Abuse and Neglect, 17, 197-212.

Zagorsky, J. L., \& White, L. (1999). NLSY79 user's guide: A guide to the 1979-1998 national longitudinal survey of youth data. Washington, DC: US Department of Labor.

Zill, N. (1990). Behavioral problems index based on parent report (Publication No. 9103). Washington, DC: Child Trends.

Zimmerman, B. J. (2000). Attaining self-regulation: A social cognitive perspective. In M. Boekaerts, P. R. Pintrich, \& M. Zeidner (Eds.), Handbook of self-regulation (pp. 13-39). San Diego, CA: Academic Press. 